\title{
Investigation of thyroid hormone status among obese women of the endocrine outpatient department in a tertiary level hospital
}

\begin{abstract}
This study was carried out to determine the thyroid hormone status among obese women attending in the endocrine outpatient department in a tertiary level hospital. From Sir Salimullah Medical College \& Hospital, Mitford, Dhaka 800 women with obesity were chosen whose ages were between 20 and 78years. In this study the weight, height, body mass index (BMI) and thyroid status (TSH and FT4 levels) were observed. Here all the women were obese according their BMI $\left(>30 \mathrm{~kg} / \mathrm{m}^{2}\right)$. Out of these 800 women, $37 \%$ (300 women) were suffering from hypothyroidism, $34.25 \%$ (274 women) with Hyperthyroidism and $15.75 \%$ (126 women) with subclinical hypothyroidism. Only $100(12.5 \%)$ women were found normal in overall criteria. This study thus reveals that the women with obesity are with greater risk for developing thyroid diseases.
\end{abstract}

Keywords: thyroid stimulating hormone, ft4, body mass index, hypothyroidism, hyperthyroidism, subclinical hypothyroidism, obese
Volume 5 Issue 4 - 2017

\author{
Kushal Biswas, Tirtha Nandi,Tanzina Bente \\ Satter, Anisur Rahman \\ Department of Pharmacy, East West University, Dhaka, \\ Bangladesh
}

Correspondence: Anisur Rahman, Department of Pharmacy, East West University, Dhaka, Bangladesh,

Email ars0193@gmail.com

Received: April 10, 2017 | Published: September 06, 2017

\section{Introduction}

Obesity can be defined as the excessive fat accumulation in the body beyond normal limit which enhances the probability of health impairment. WHO defines that person obese who's BMI is equal to or more than $30 \mathrm{~kg} / \mathrm{m}^{2}{ }^{1}$ It is a condition of excess body fat, is relatively random and usually based on an approximation of body fat which is called the body mass index (BMI). ${ }^{2} \mathrm{BMI}$, a numerical value used to indicate the approximation of the body fat, is derived from the weight and height of an individual. It is calculated by dividing the mass in kilogram by the square of height of a person in meter unit. ${ }^{3,4}$ The exact cause of obesity is still a matter to be unearthed. However, it is evident that an imbalance in energy input and output contributes significantly for the development of obesity. When a person consumes more calories than he or she burns by exercise or physiological activities, the extra calories accumulate inside the body. And the ultimate consequence is overweight and obesity. ${ }^{5-7}$ However, there are other factors which are directly or indirectly contribute for the development of obesity of an individual. Family studies suggest that heredity may explain up to $67 \%$ of the population variance in BMI. ${ }^{8,9}$ Obesity is associated with an increased risk of diabetes, dyslipidemia, kidney disease, cardiovascular disease, all-cause mortality and cancer. ${ }^{10,11}$ As a consequence, in developed countries, increasing rates of obesity may lead to a decline in the overall life expectancy. ${ }^{12}$ Thyroid is an endocrine gland which is located at the base of our neck. It releases hormones which controls metabolism. Two main hormones are released from thyroid gland- triidothyronine (T3) and thyroxine (T4). Thyroid gland uses iodine obtained from food to produce these two important hormones. The hypothalamus produces Thyrotropin-Releasing Hormone (TRH) that signals the pituitary to induce the thyroid gland to produce more or less of T3 and $\mathrm{T} 4$ by either increasing or decreasing the release of a hormone called thyroid stimulating hormone (TSH) ${ }^{13-15}$ It is important that the concentrations of $\mathrm{T} 3$ and $\mathrm{T} 4$ in the blood are neither too high nor too low. Depending on serum thyroid status, there are mainly three types of thyroid diseases including Hypothyroidism, Hyperthyroidism and Subclinical hypothyroidism. ${ }^{16}$ Hypothyroidism is a condition in which the body is not able to produce enough thyroid hormones, or is unable to respond or utilize existing thyroid hormones properly. Symptoms include fatigue, low energy, weight gain, bradycardia, sensitivity to cold temperatures, constipation, depressed mood or memory difficulty. ${ }^{17,18}$ Hyperthyroidism is another condition in which the body is producing too much thyroid hormone. Symptoms include difficulty sleeping (insomnia), irritability, panic attacks, weight loss despite having a good appetite, tachycardia or palpitations, sensitivity to hot temperatures, increased bowel movements or diarrhea, tremors, excess sweating and/or warm skin. ${ }^{19}$ Subclinical hypothyroidism (SCH) is defined as a serum thyroid-stimulating hormone (TSH) level above the upper limit of normal despite normal levels of serum free thyroxine. ${ }^{20}$ Obesity and thyroid dysfunction are common diseases. Hypothyroidism has often thought to be the cause of obesity. In recentyears, there has been an increasing attention to thyroid function in obese patients. ${ }^{21-23}$ But the prevalence of hypothyroidism among obese women is not known in our country. The finding of the study might give the clinicians an idea regarding the investigation of thyroid hormone status in obese women and consequently they will be particularly alert for the screening their thyroid dysfunction.

\section{Materials and methods}

A total of 800 patients with relevant symptoms were initially included in the study. The main outcome variable of the study is to determine the investigation of thyroid hormone status among obese women attending in the endocrine outpatient department in a tertiary level hospital. Women participated in the endocrine outpatient department whose BMI $\geq 25 \mathrm{~kg} / \mathrm{m}^{2}$ were the study population. Some other criteria were also maintain like, BMI $\geq 25 \mathrm{~kg} / \mathrm{m}^{2}$, Age $>18$ years and with clinical features of hypothyroidism, hyperthyroidism and subclinical may hypothyroidism or not present. Some women were excluded from the study (e.g. pregnant women, Patient with secondary Hypothyroidism, Thyroid carcinoma and $\mathrm{BMI}<25 \mathrm{~kg} / \mathrm{m}^{2}$ ) 


\section{Procedure of preparing \& organizing materials}

Data were collected using a structured questionnaire (Research Instrument) containing all the variables of interest. Collected data were checked daily in Sir Salimullah Medical College and Hospital, Mitford, Dhaka. Data collection periods were October, 2015 to September, 2016. Height was taken using standard apparatus with the subjects wearing light clothing and without shoes. Weight was measured in the upright position with a weighting scale to the nearest 0.01 kilogram $(\mathrm{kg})$. Height was measured to the nearest $0.1 \mathrm{~cm}$ by using a non-stretching tape. Obesity index or body mass index (BMI) was calculated as weight $(\mathrm{kg})$ divided by height squared $\left(\mathrm{m}^{2}\right)$ to estimate overall body fat distribution. ${ }^{24}$

\section{Procedure of data collection}

Data were collected by interviewing the patients, anthropometric measurements and laboratory investigations. Data were collected ensuring the privacy and confidentiality as far as possible. Before data collection, the detail of the study was explained to each eligible respondent and written informed consent was taken.

\section{Data analysis}

The data was analyzed by one-way ANOVA followed by Dunnet test to estimate significant differences between the test and control groups with Graph Pad Prism Data Editor for Windows, Version 6.0 (GraphPad Software Inc., San Diego, CA).

\section{Result and discussion}

The study was done among 800 obese women patients with ages ranging from 20 to $78 y$ rs. Several related information regarding to study was also collected from the patients like weight, height, BMI and thyroid status report were taken. According to this study, the highest numbers of obese women patients were found between age ranges from 28- 37yrs (Figure 1). More than 44\% of total patients are belonging here. Second large number was found between age ranges 18 to 27 years, with the number of 236 . After age of 37 the number of patients declines for each group. In age group 38-47years patients' number was 140, in 48-57years group number was 54 and in 48-57years group number was 12 . The least number of patients was found in age group 68 and above, where it was only 4.

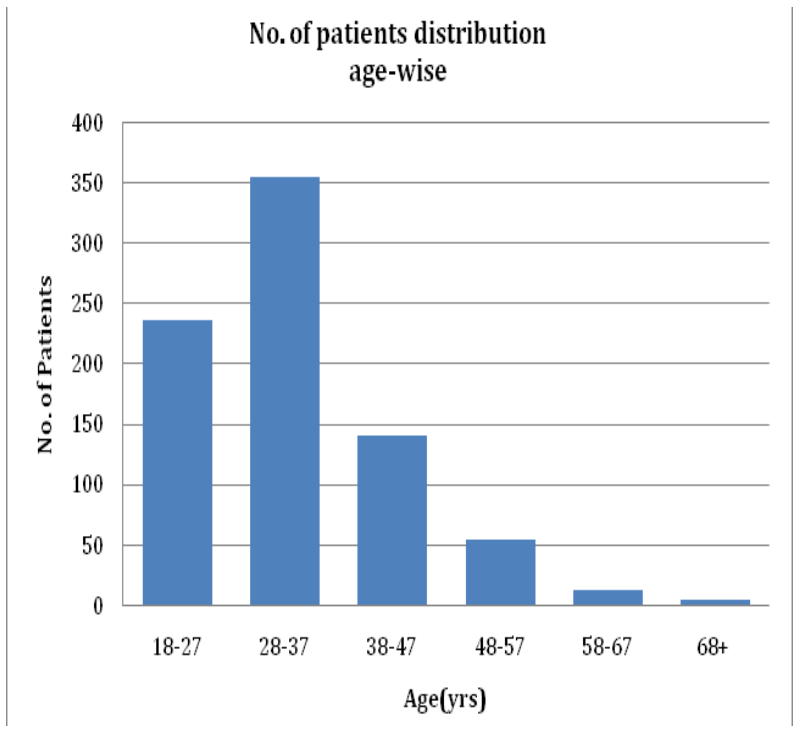

Figure I Patients number in different age group.
According to BMI most of the patients were fall into the BMI range between $41-50 \mathrm{~kg} / \mathrm{m}^{2}$. Nearly $62 \%$ patients (500 in total) were in belonging to this group (Figure 2). 240 patients having the BMI range of $30-40 \mathrm{~kg} / \mathrm{m}^{2}$ while only 60 out of 800 patients were in the $\mathrm{BMI}$ range of $52-60 \mathrm{~kg} / \mathrm{m}^{2}$. (P value 0.472 )

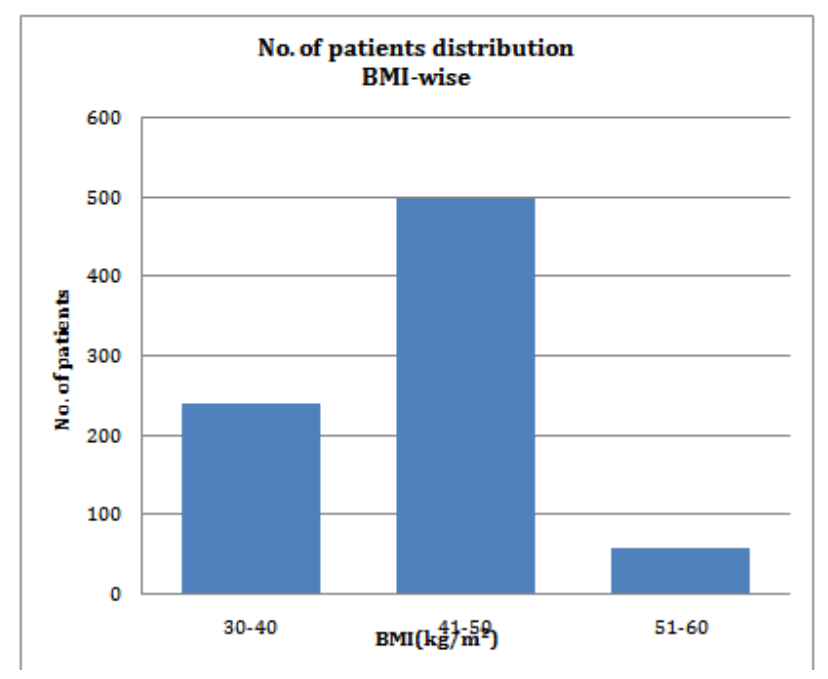

Figure 2 Number of patient according to BMI.

Body composition and thyroid function are appearing to be closely related. It was also found positive in our study. $37 \%$ of our total study population was suffering from hypothyroidism (total number 300), where 274 female were found in Hyperthyroidism and 126 found in subclinical hypothyroidism condition respectively (Figure 3 ). Only 100 in total 800 populations found normal in overall criteria. (P value $0.451)$

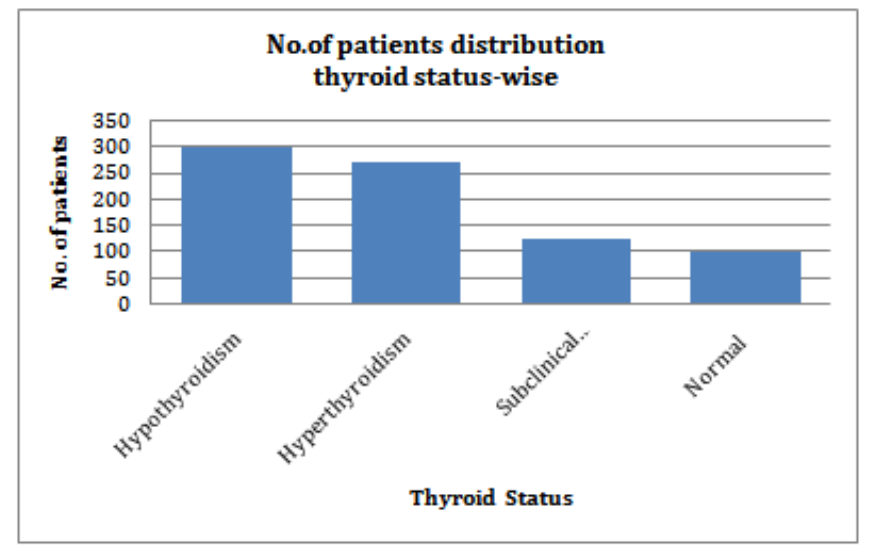

Figure 3 Number of patient according to thyroid function.

\section{Discussion}

Thyroid hormones are manly involved in regulating basal metabolism, food intake, fat oxidation, and thermogenesis and play an important role in lipid and glucose metabolism. Thyroid dysfunction is associated with changes in body weight and composition and body temperature. ${ }^{25}$ Hypothyroidism is generally found with decreased thermogenesis, decreased metabolic rate, and has also been shown to correlate with a higher body mass index (BMI) and a higher prevalence of obesity. When TSH levels are high from normal level and FT4 levels are reduced from normal levels, then hypothyroidism is occurred. There are also some clinical evidence which suggests that even mild thyroid dysfunction in the form of subclinical 
hypothyroidism is linked to significant changes in body weight and represents a risk factor for overweight and obesity. ${ }^{26}$ In our study we also found the same scenario. Among all 800 populations we found $37 \%$ patient are suffering from Hypothyroidism and $16 \%$ of them also in the line of subclinical hypothyroidism. There was a good number obese population in our study also suffers from hyperthyroidism. In hyperthyroidism the TSH level are at the upper limit of the normal range and are positively correlated with the BMI. Low FT4 with a moderate increase in $\mathrm{T} 3$ or free $\mathrm{T} 3$ levels has been reported in obese subjects in several studies. 274 out of 800 study populations are suffering from hyperthyroidism. Only 100 obese female from our total study subjects appears to have normal thyroid level.

\section{Conclusion}

From the above study we can conclude that thyroid hormone dysfunction is common in obese female, where hypothyroidism is predominant. Beside this Hyperthyroidism and subclinical hypothyroidism are also frequent in female obese people.

\section{Acknowledgements}

None.

\section{Conflict of interest}

Author declares that there is no conflict of interest.

\section{References}

1. World Health Organization. Obesity and overweight. 2016.

2. Tchernof A, Després JP. Pathophysiology of human visceral obesity: an update. Physiol Rev. 2013;93(1):359-404.

3. Garrouste-Orgeas M, Troché G, Azoulay E, et al. Body mass index. Intensive Care Medicine. 2004;30(3):437-443.

4. Wolk R, Berger P, Lennon RJ, et al. Body mass index. Circulation. 2003;108(18):2206-2211.

5. Overweight and Obesity Statistics. 2017.

6. Cao H. Adipocytokines in obesity and metabolic disease. J Endocrinol. 2014;220(2):T47-T59.

7. Berg KC, Peterson CB, Crosby RD, et al. Relationship between daily affect and overeating-only, loss of control eating-only, and binge eating episodes in obese adults. Psychiatry Res. 2014;215(1):185-191.

8. Aguer C, Pasqua M, Thrush AB, et al. Increased proton leak and SOD2 expression in myotubes from obese non-diabetic subjects with a family history of type 2 diabetes. Biochim Biophys Acta. 2013;1832(10):1624-1633.

9. Cederberg H, Stančáková A, Kuusisto J, et al. Family history of type 2 diabetes increases the risk of both obesity and its complications: is type 2 diabetes a disease of inappropriate lipid storage? J Intern Med. 2015;277(5):540-551.
10. Lean MEJ. Pathophysiology of obesity. Proc Nutr Soc. 2000;59(3):331-336.

11. Golden SH, Robinson KA, Saldanha I, et al. Prevalence and incidence of endocrine and metabolic disorders in the United States: a comprehensive review. The Journal of Clinical Endocrinology \& Metabolism. 2009;94(6):1853-1878.

12. Olshansky SJ, Passaro DJ, Hershow RC, et al. A potential decline in life expectancy in the United States in the 21th century. $N$ Engl $J$ Med. 2005;352(11):1138-1145.

13. Chiamolera MI, Wondisford FE. Thyrotropin-releasing hormone and the thyroid hormone feedback mechanism. Endocrinology. 2009;150(3):1091-1096.

14. Bastenie PA, Ermans AM. Thyroiditis and thyroid function: clinical, morphological, and physiopathological studies. Elsevier; 1972. p. 1-356.

15. Fonseca TL, Correa-Medina M, Campos MP, et al. Coordination of hypothalamic and pituitary T3 production regulates TSH expression. $J$ Clin Invest. 2013;123(4):1492-1500.

16. Laurberg P, Cerqueira C, Ovesen L, et al. Iodine intake as a determinant of thyroid disorders in populations. Best Pract Res Clin Endocrinol Metab. 2010;24(1):13-27.

17. Vaidya B, Pearce SH. Clinical Review-Management of hypothyroidism in adults. $B M J .2008 ; 337(7664): 284-289$.

18. Sorensen JR, Winther KH, Bonnema SJ, et al. Respiratory Manifestations of Hypothyroidism: A Systematic Review. Thyroid. 2016;26(11):1519-1527.

19. Allahabadia A, Daykin J, Sheppard MC, et al. Radioiodine treatment of hyperthyroidism-prognostic factors for outcome. J Clin Endocrinol Metab. 2001;86(8):3611-3617.

20. Fatourechi V. Subclinical hypothyroidism: an update for primary care physicians. Mayo Clinic Proceedings. 2009;84(1):65-71.

21. Biondi B. Thyroid and Obesity: An Intriguing Relationship. J Clin Endocrinol Metab. 2010;95(8):3614-3617.

22. Rotondi M, Magri F, Chiovato L. Thyroid and Obesity: Not a One-Way Interaction. J Clin Endocrinol Metab. 2011;96(2):344-346.

23. Longhi S, Radetti G. Thyroid function and obesity. J Clin Res Pediatr Endocrinol. 2013;5(Suppl 1):40-44.

24. Khalil B, Khodadad M, Pourjafar M, et al. Serum thyroid hormones and trace element concentrations in crossbred holstein cattle naturally infected with Theileria annulata. Comparative Clinical Pathology. 2011;20(2):115-120.

25. Rosenbaum M, Hirsch J, Murphy E, et al. Effects of changes in body weight on carbohydrate metabolism, catecholamine excretion, and thyroid function. Am J Clin Nutr. 2000;71(6):1421-1432.

26. Sanyal D, Raychaudhuri M. Hypothyroidism and obesity: An intriguing link. Indian J Endocrinol Metab. 2016;20(4):554-557. 